\title{
Leakage Current Degradation of Gallium Nitride Transistors Due to Heavy Ion Tests
}

\author{
Brian D. Olson, J. David Ingalls, Casey H. Rice, Casey C. Hedge, Patrick L. Cole, Adam R. Duncan, \\ and Sarah E. Armstrong, Member, IEEE
}

\begin{abstract}
Commercial gallium nitride high-electron mobility transistors are tested at Texas A\&M University cyclotron. Degradation of gate and drain currents is characterized.
\end{abstract}

\section{INTRODUCTION}

Gallium nitride $(\mathrm{GaN})$ is emerging as an attractive,

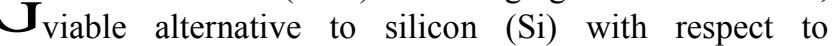
temperature, power, and high-speed applications. Early studies in radiation effects in GaN focus on light-emitting diode (LED) applications [1] but show promise from a hardness standpoint. Heavy ion testing of $\mathrm{GaN}$ high electron mobility transistors (HEMTs) has caused gate and drain leakage current degradation, potentially due to single event gate rupture (SEGR) [2], [3].

The devices tested are commercial off the shelf (COTS) high-electron mobility transistors (HEMTs). A sample GaN HEMT device structure is shown in Figure 1. These are majority carrier devices with a thin $\mathrm{AlGaN}$ layer for electron generation. An in-situ x-ray experiment and 8 heavy ion experiments were performed. The focus of the experiments was to characterize the gate and drain current degradations in a heavy ion environment as seen in [2], [3], and [4]. To enhance understanding of the mechanisms, x-ray irradiation was performed to investigate possible mechanisms difficult to isolate in the heavy ion test setting.

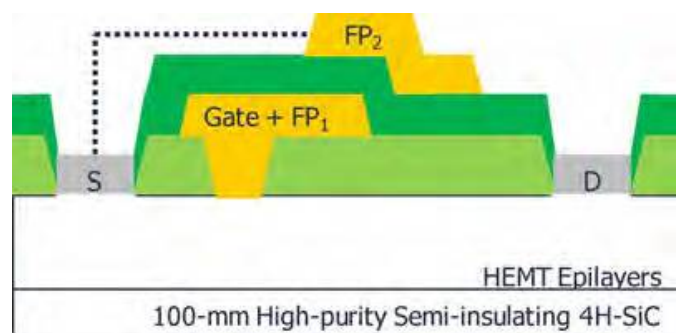

Figure 1: GaN HEMT structure. Figure adapted from [5].

Manuscript received July 12, 2015. This work was supported in part by NSWC Crane's Naval Innovation in Science and Engineering (NISE) funding.

B. D. Olson, J. D. Ingalls, C. H. Rice, C. C. Hegde, P. L. Cole, A. R. Duncan, and S. E. Armstrong are with the Naval Surface Warfare Center, Crane Division, Crane, IN USA (telephone: 812-854-6385, email: brian.d.olson1@navy.mil).

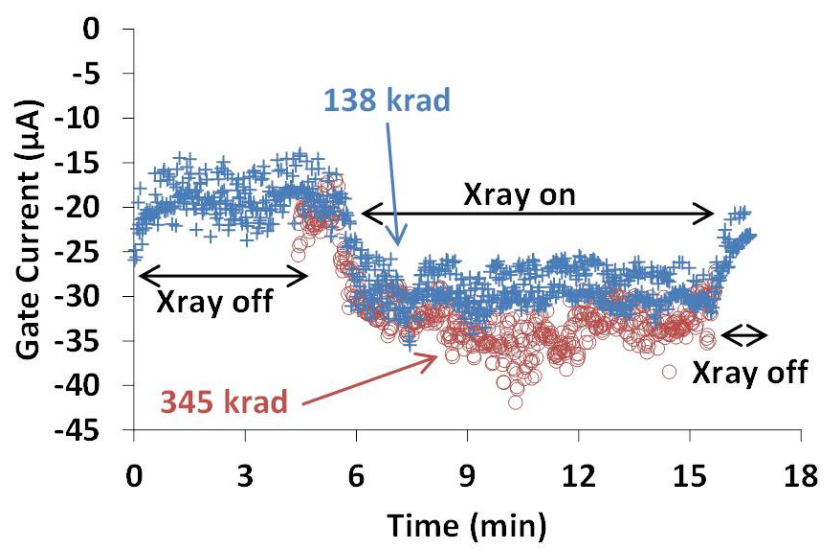

Figure 2: Gate current leakage measured in situ with Comet X-ray irradiation. The DUT was irradiated to $138 \mathrm{krad}(\mathrm{CaF} 2)$, and irradiated again to $345 \mathrm{krad}(\mathrm{CaF} 2)$.

\section{EXPERIMENTAL DETAILS}

\section{A. NSWC Crane Comet X-ray}

A set of x-ray exposures was performed in a Comet X-ray chamber at the Naval Surface Warfare Center (NSWC) Crane. The chamber is specially designed for radiation effects testing. It consists of an $\mathrm{x}$-ray tube with a tungsten target that can provide beam currents ranging from 0.5 to $45 \mathrm{~mA}$ with accelerating voltages from $10 \mathrm{keV}$ to $160 \mathrm{keV}$. In addition, the device under test (DUT) can be placed in a range from less than an inch to 21 inches away from the output of the $\mathrm{x}$ ray tube. All of these variables allow for testing with dose rates ranging from less than $0.1 \mathrm{rad}(\mathrm{Si}) / \mathrm{s}$ to over $1200 \mathrm{rad}(\mathrm{Si}) / \mathrm{s}$.

The delidded transistor was irradiated from the front side of the die in the Comet x-ray system with an energy of $160 \mathrm{keV}$ and beam current of $28.1 \mathrm{~mA}$. The device was biased in pinch-off $(\mathrm{Vg}=-5 \mathrm{~V}$ and $\mathrm{Vd}=28 \mathrm{~V})$ for the tests. A 10 minute exposure was performed at 9 inches from the tube head corresponding to $138 \mathrm{krad}\left(\mathrm{CaF}_{2}\right)$. A second biased 10 minute exposure was performed at 6 inches from the tube head corresponding to $345 \mathrm{krad}\left(\mathrm{CaF}_{2}\right)$.

Results showing gate leakage of the DUT with respect to time are shown in Figure 2. Start and stop times for the source are indicated on the graph. It is clear that the gate current increases during exposure, but no permanent degradation was observed. 
TABLE 1: CHARACTERISTICS OF THE TEST IONS. THE ENERGIES AND LET WERE DETERMINED USING THE PROGRAM SRIM TO PRODUCE TABLES OF ENERGY LOSS AT THE FULL RANGE OF ENERGY.

\begin{tabular}{|c|c|c|c|c|c|c|}
\hline Ion & $\begin{array}{c}\text { Ion Beam Energy } \\
{[\mathrm{MeV}]}\end{array}$ & E0 $[\mathrm{MeV}]$ & $\begin{array}{c}\text { LET on GaN } \\
{\left[\mathrm{MeV} / \mathrm{mg} / \mathrm{cm}^{2}\right]}\end{array}$ & $\begin{array}{c}\text { LET on } \mathrm{Si} \\
{\left[\mathrm{MeV} / \mathrm{mg} / \mathrm{cm}^{2}\right]}\end{array}$ & $\begin{array}{c}\text { dE/dx on GaN } \\
{[\mathrm{MeV} / \mu \mathrm{m}]}\end{array}$ & $\begin{array}{c}\mathrm{dE} / \mathrm{dx} \text { on } \mathrm{Si} \\
{[\mathrm{MeV} / \mu \mathrm{m}]}\end{array}$ \\
\hline 197-Au & 2955 & 1523 & 70.5 & 89.7 & 43.3 & 20.8 \\
\hline 181-Ta & 2715 & 1423 & 63.8 & 81.2 & 39.3 & 18.9 \\
\hline 165-Нo & 2475 & 1317 & 57.1 & 72.7 & 35.2 & 17.0 \\
\hline 141-Pr & 2115 & 1060 & 53.3 & 67.9 & 32.8 & 15.8 \\
\hline $129-\mathrm{Xe}$ & 1935 & 959 & 50.3 & 64.2 & 30.9 & 14.9 \\
\hline $109-\mathrm{Ag}$ & 1635 & 876 & 40.4 & 51.3 & 24.9 & 11.9 \\
\hline
\end{tabular}

\section{B. Texas A\&M University Cyclotron}

The testing conducted at Texas A\&M University (TAMU) includes a series of experiments developed to explore leakage issues identified in [2], [3], and during previous experiments at the same facility. The beam characteristics for this test have been modeled using SRIM software and are given in Table 1. The second table column, Ion Beam Energy is the original beam energy produced by the cyclotron for each ion. The column E0 is the energy of the beam after it has been degraded by the exit window, the air gap, and a $0.5 \mu \mathrm{m} \mathrm{SiN}$ passivation layer. It is the energy of the ions as they are hitting the sensitive layer of the transistor. The top layers of the device are typically very thin, for example, the Cree process is a $25 \mathrm{~nm}$ layer of $\mathrm{Al}_{0.22} \mathrm{Ga}_{0.78} \mathrm{~N}$ on top of a $0.6 \mathrm{~nm}$ AlN barrier layer, and then $1.4 \mu \mathrm{m}$ of Fe-doped GaN [5]. The LET varies little throughout these thin layers (i.e. volume of the active region), so only GaN was modeled for simplicity. If the beam were to travel through an added $1.5 \mathrm{um}$ thickness of $\mathrm{GaN}$, then the $\mathrm{dE} / \mathrm{dX}$ and LET would change by approximately $0.5 \%$.

The LET and dE/dx of interest are those of GaN. There is no $\mathrm{Si}$ layer in the GaN transistors. The LET equivalents for $\mathrm{Si}$ are given for comparison for those readers more familiar with tests on Silicon devices. The difference between $\mathrm{Si}$ and GaN for the LET and $\mathrm{dE} / \mathrm{dx}$ are due to the different material densities and different number of electrons per unit cell.

Testing was done to observe leakage in the DUT during DC bias conditions. The test setup and equipment are shown in Table 2 and Figure 3. The manufacturer's demonstration board was used to interface the amplifiers to the test equipment to ensure proper matching. The board was attached to a heat sink to manage thermal dissipation during testing.

TABLE 2: TEST EQUIPMENT USED FOR DC HEAVY ION EXPERIMENTS SHOWN IN FIGURE 3

\begin{tabular}{ll} 
Test Equipment & Model \\
\hline Gate Source Meter & Keithley 2410 \\
Drain Source Meter & Keithley 2430 \\
\hline
\end{tabular}

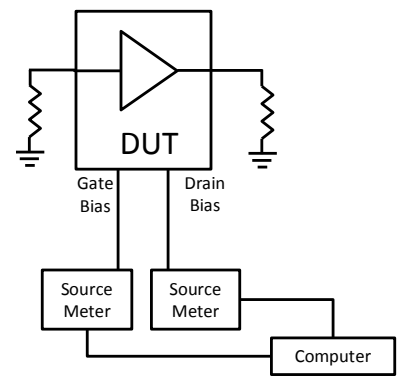

Figure 3: DC test setup for TAMU testing.

Drift of the gate and drain currents were measured by monitoring a device biased in pinch-off $(\mathrm{Vg}=-5 \mathrm{~V}$ and $\mathrm{Vd}=28 \mathrm{~V}$ ) for 44 minutes. This experiment was performed in the TAMU cyclotron heavy ion test cave, but with the beam shutter closed. Results are shown in Figure 4.

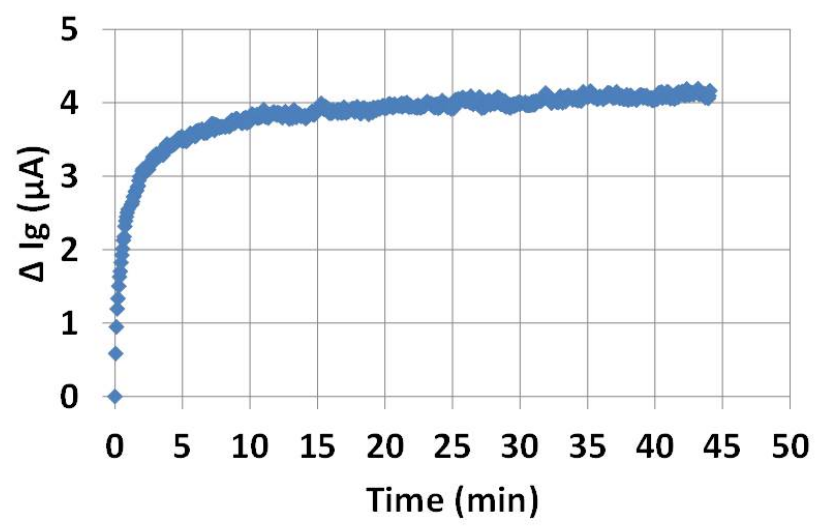

(a)

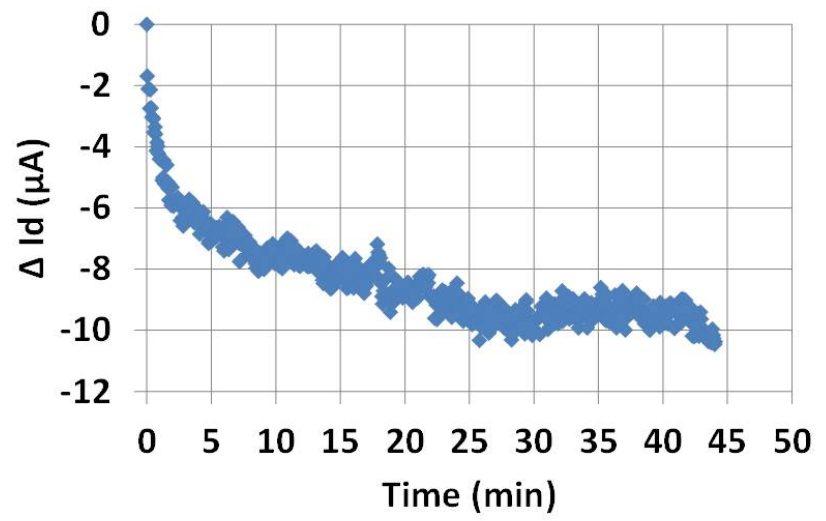

(b)

Figure 4: Unirradiated (a) gate and (b) drain currents. 


\begin{tabular}{ll} 
Experiment \# & Description \\
\hline 1 & Effect of Repeated Exposures \\
2 & Effect of Drain Bias \\
3 & Effect of Gate Bias - Drain Off \\
4 & Effect of Gate Bias - Drain On \\
5 & Effect of Ion Energy \\
6 & Effect of Incident Angle \\
7 & RF Drive \\
8 & Effects of Varying Ions \\
\hline
\end{tabular}

The completed series of experiments, including purpose, bias conditions, and desired outputs are outlined in the following section of this summary. Table 3 provides a lookup table of the experiments.

1) Experiment 1-Repeated exposures

The purpose of this experiment is to observe changes in leakage currents across repeated heavy ion exposures; a 5 minute rest period followed each irradiation. The device was biased in pinch-off $(\mathrm{Vg}=-5 \mathrm{~V}$ and $\mathrm{Vd}=28 \mathrm{~V})$ during both irradiation and rest periods. An Id- Vg sweep was done before each irradiation and at the conclusion of the experiment. Two DUTs, P/Ns 5 and 6, were irradiated with Au. P/N 5 was irradiated to fluences of $1.2 \times 10^{7}, 1.5 \times 10^{7}$, and $2.0 \times 10^{7}$ particles $/ \mathrm{cm}^{2}, \mathrm{P} / \mathrm{N} 6$ was irradiated to a fluence of $2.0 \times 10^{7}$ for each exposure.

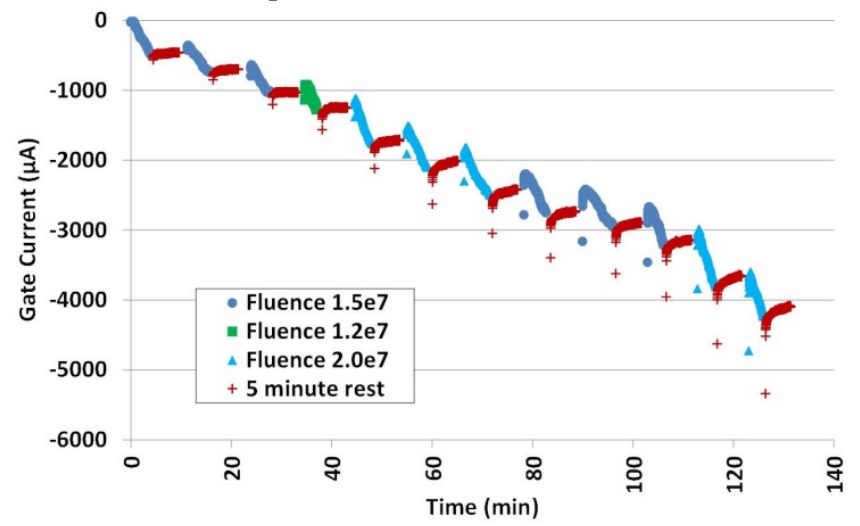

(a)

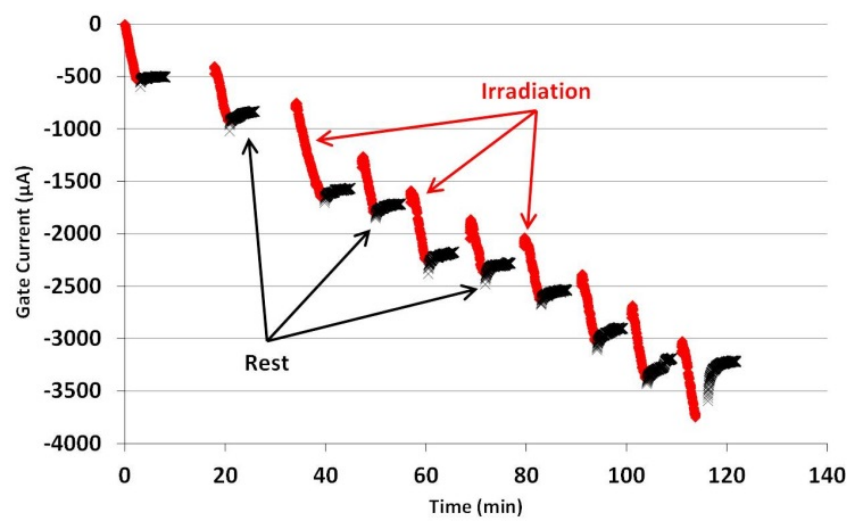

(b)

Figure 5: Gate current measured in situ with repeated Au irradiation for (a) $\mathrm{P} / \mathrm{N} 5$ and (b) P/N 6. The DUTs were biased in pinch-off for both irradiations and rest periods.

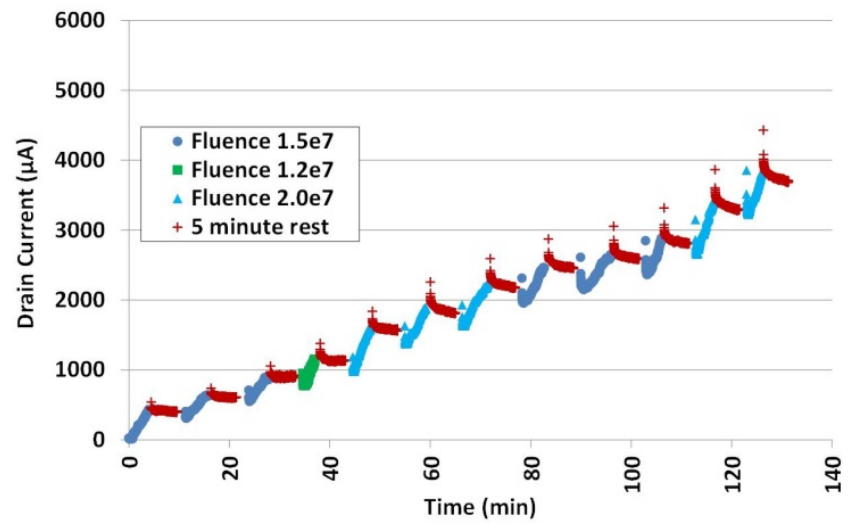

(a)

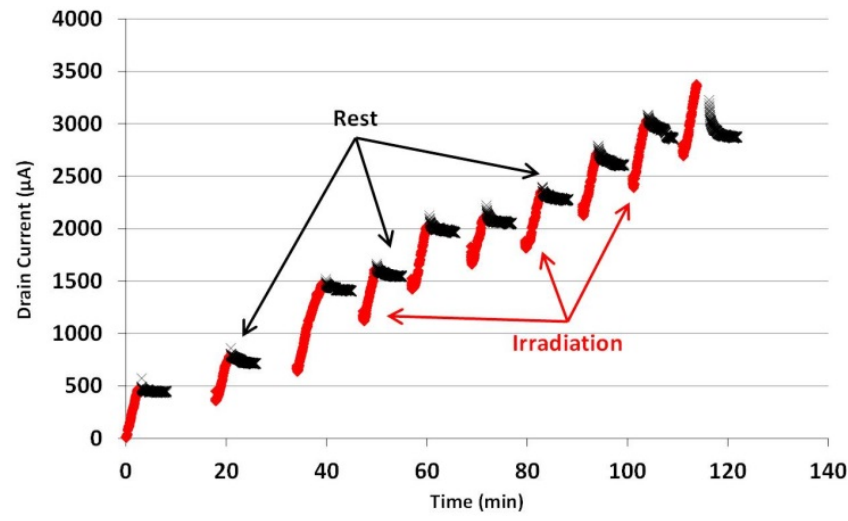

(b)

Figure 6: Drain current measured in situ with repeated Au irradiation for (a) $\mathrm{P} / \mathrm{N} 5$ and (b) P/N 6. The DUTs were biased in pinch-off for both irradiations and rest periods.

Figures 5 and 6 show gate and drain current increasing with each subsequent exposure and minimal annealing during the rest periods. This is also illustrated in the Ig-Vg sweeps in Figure 6. Id-Vg sweep data are shown in Figures 8 and 9, with the former on a linear scale and the latter on a log-linear scale to highlight the increase in drain current in pinch-off conditions with each irradiation in Experiment 1.

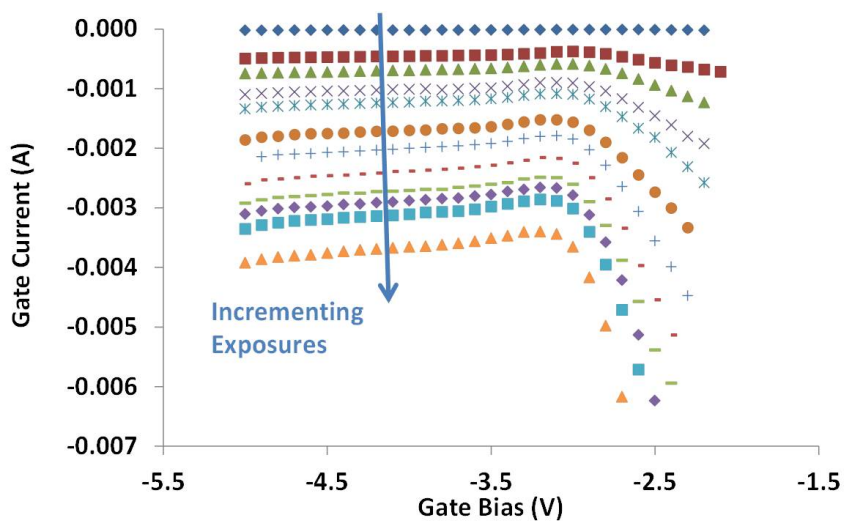

(a) 


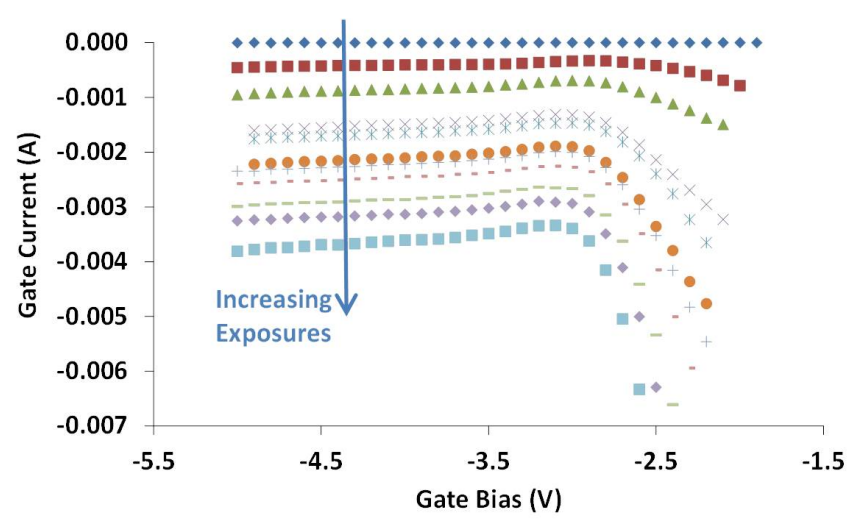

(b)

Figure 7: Gate current was measured versus a sweep of the gate bias before each irradiation and at the conclusion of the test for (a) P/N 5 and (b) P/N 6 . Drain was biased to $28 \mathrm{~V}$.

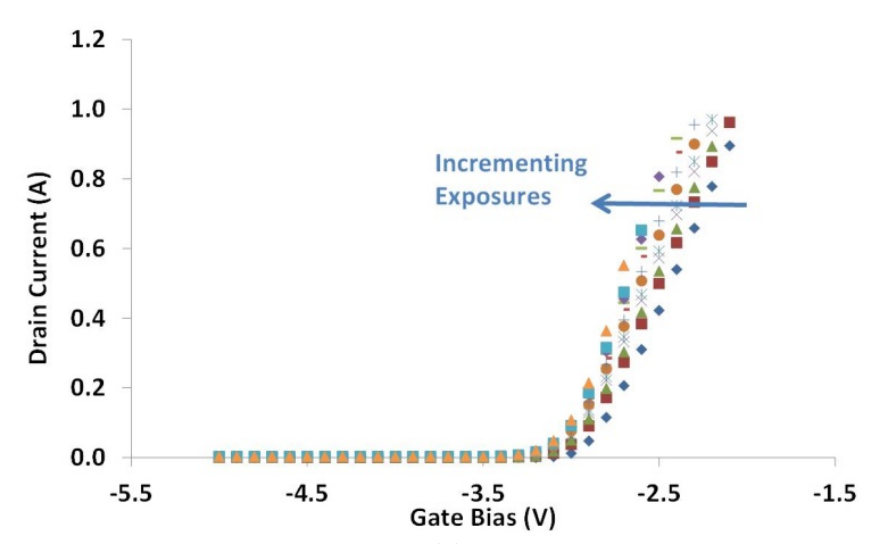

(a)

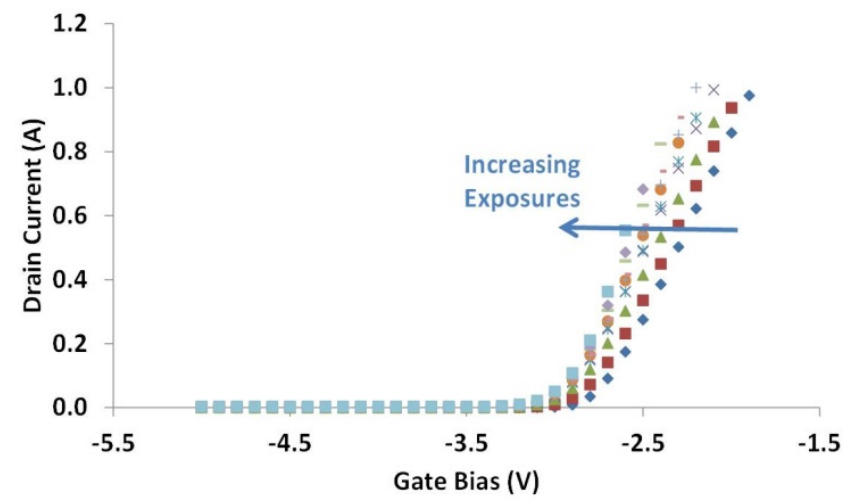

(b)

Figure 8: Drain current was measured versus a sweep of the gate bias before each irradiation and at the conclusion of the test for (a) P/N 5 and (b) P/N 6 . Drain was biased to $28 \mathrm{~V}$.

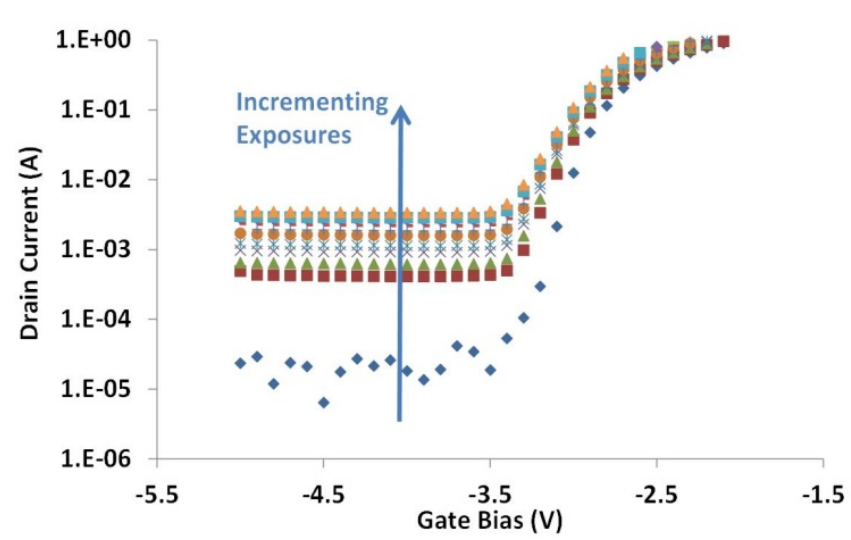

(a)

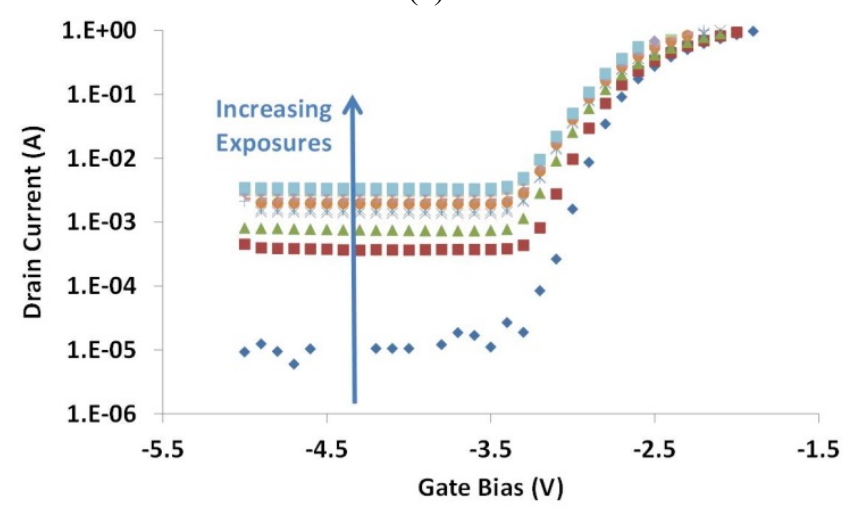

(b)

Figure 9: Same data as Figure 8 for (a) P/N 5 and (b) P/N 6 except drain current plotted on a semi-log scale.

Data from Figures 7 and 8 are summarized in Figure 10. A single data point $\left(\mathrm{V}_{\mathrm{G}}=-4.9 \mathrm{~V}, \mathrm{~V}_{\mathrm{D}}=28 \mathrm{~V}\right)$ is recorded from each data set and plotted with respect to the accumulated fluence of the devices. In this figure, solid icons represent data from $\mathrm{P} / \mathrm{N} 5$; unfilled icons represent data from $\mathrm{P} / \mathrm{N} 6$.

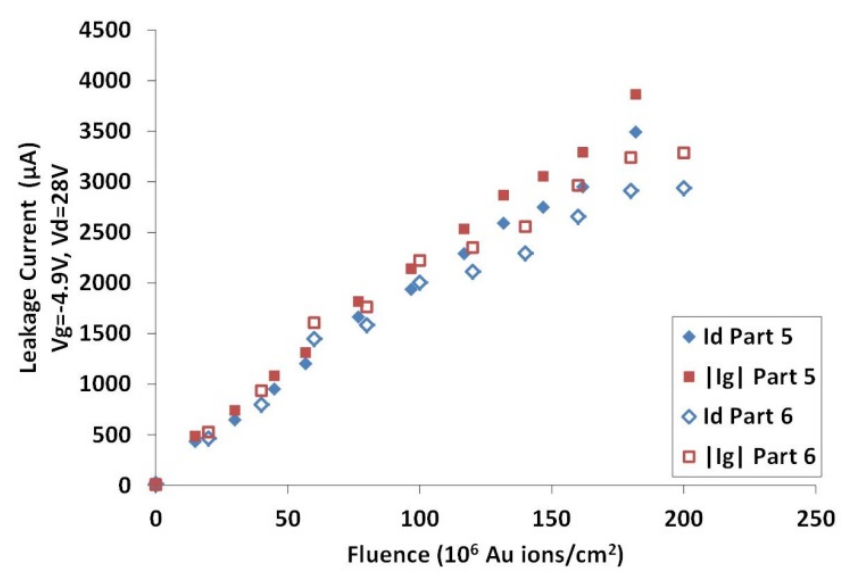

Figure 10: The magnitude of gate and drain leakage currents at gate voltage $-4.9 \mathrm{~V}$ and drain voltage $28 \mathrm{~V}$ before each irradiation and at the conclusion of the test.

2) Experiment 2 - Drain bias

The purpose of this experiment is to observe changes in leakage currents with respect to drain bias; a 5 minute rest period followed each irradiation. During irradiation, a gate bias of $-5 \mathrm{~V}$ was applied to pinch-off the conduction channel. 
Drain bias was incremented for each exposure from $0 \mathrm{~V}$ to $40 \mathrm{~V}$ in $10 \mathrm{~V}$ steps for $\mathrm{P} / \mathrm{N} 7$. Drain bias was decremented for each exposure from $40 \mathrm{~V}$ to $0 \mathrm{~V}$ in $-10 \mathrm{~V}$ steps for $\mathrm{P} / \mathrm{N} 8$. The devices were biased in pinch-off $(\mathrm{Vg}=-5 \mathrm{~V}$ and $\mathrm{Vd}=28 \mathrm{~V})$ for the rest period. An Ig-Vg sweep was done before each irradiation and at the conclusion of the experiment. The two parts were irradiated with $\mathrm{Au}$ up to a fluence of $2.0 \times 10^{7}$ particles $/ \mathrm{cm}^{2}$ for each exposure. Results are shown in Figures $11 \& 12$.

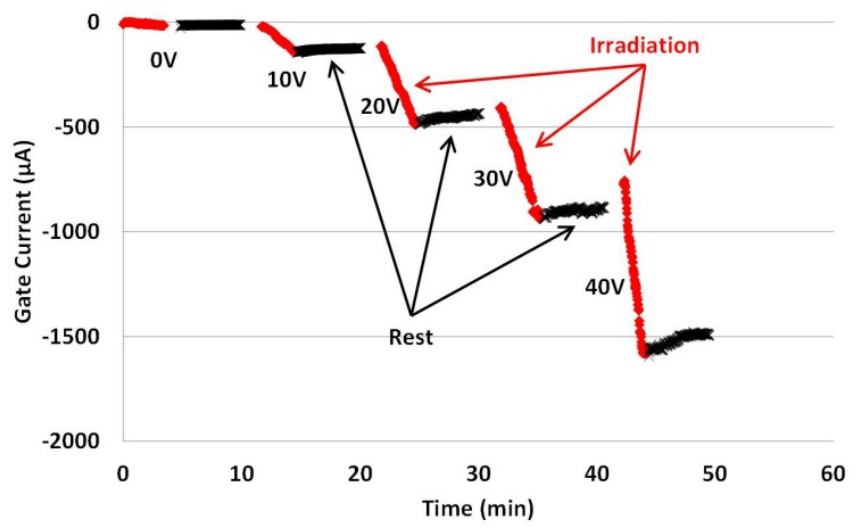

(a)

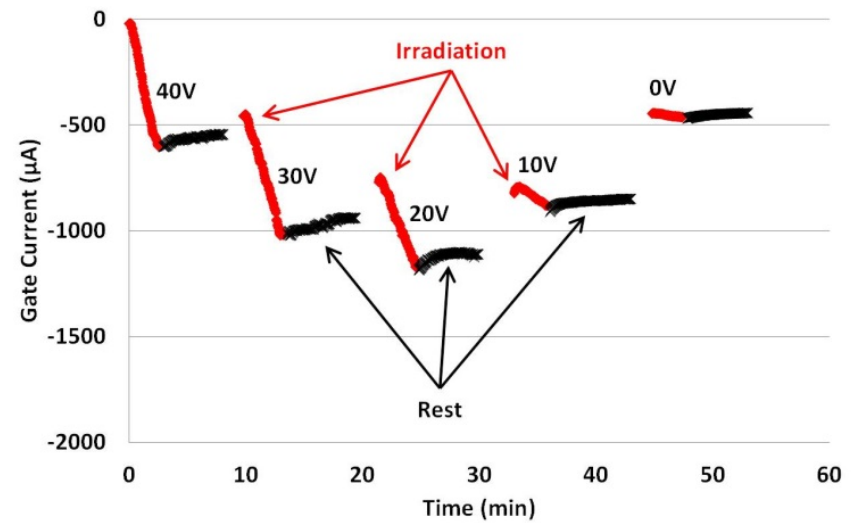

(b)

Figure 11: Gate current measured in situ with repeated Au irradiation and gate biased at $-5 \mathrm{~V}$. (a) Drain bias was incremented for each exposure from $0 \mathrm{~V}$ to $40 \mathrm{~V}$ in $10 \mathrm{~V}$ steps for $\mathrm{P} / \mathrm{N}$ 7. (b) Drain bias was decremented for each exposure from $40 \mathrm{~V}$ to $0 \mathrm{~V}$ in $-10 \mathrm{~V}$ steps for $\mathrm{P} / \mathrm{N} 8$.

\section{3) Experiment 3 - Gate bias - Drain Off}

The purpose of this experiment is to observe changes in leakage currents with respect to gate bias; a 5 minute rest period followed each irradiation. During irradiation, a drain bias of $0 \mathrm{~V}$ was applied to minimize potential conduction between the drain and source. Gate bias was decreased from $0 \mathrm{~V}$ to $-10 \mathrm{~V}$ in $-2 \mathrm{~V}$ steps for repeated irradiations. The device was biased in pinch-off $(\mathrm{Vg}=-5 \mathrm{~V}$ and $\mathrm{Vd}=28 \mathrm{~V})$ for the rest period. An Ig-Vg and Id-Vg sweeps were performed before each irradiation and at the conclusion of the experiment. Each exposure irradiated one part with $\mathrm{Au}$ to a fluence of $3.0 \times 10^{7}$ particles $/ \mathrm{cm}^{2}$. Results are shown in Figures $13 \& 14$.

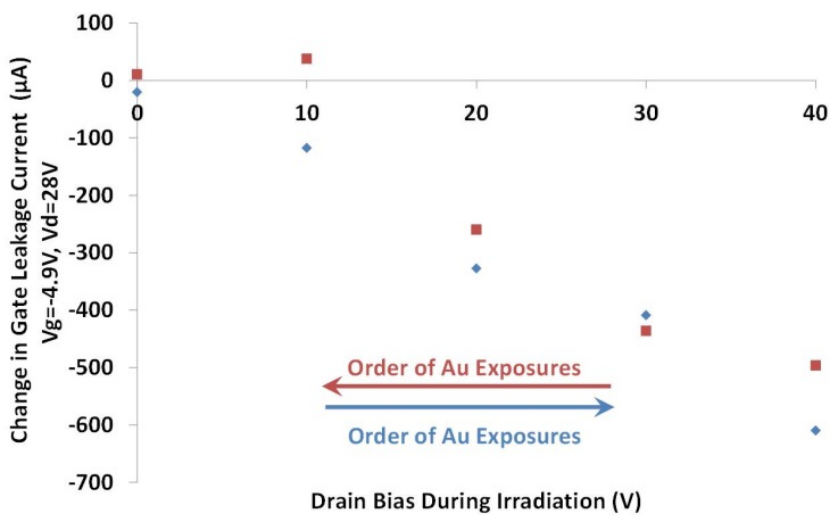

Figure 12: The change in gate leakage current with respect to the irradiated drain bias for both $\mathrm{P} / \mathrm{N} 7$ (blue) and $\mathrm{P} / \mathrm{N} 8$ (red) is plotted. This data is from the $-4.9 \mathrm{~V}$ and drain voltage $28 \mathrm{~V}$ data point for the Ig-Vg sweep before each irradiation and at the conclusion of the test.

Since the irradiated drain and source biases are both at the same potential $(0 \mathrm{~V})$, the measured leakage current at the drain terminal is between the drain and gate. This means the source-to-gate leakage current can be calculated by subtracting the measured drain current from gate current. The calculated Isg is shown in Figure 13.

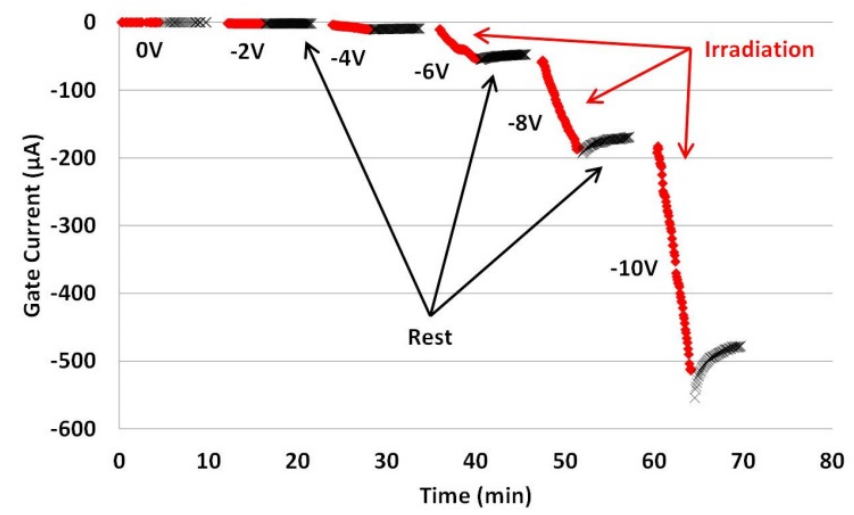

(a)

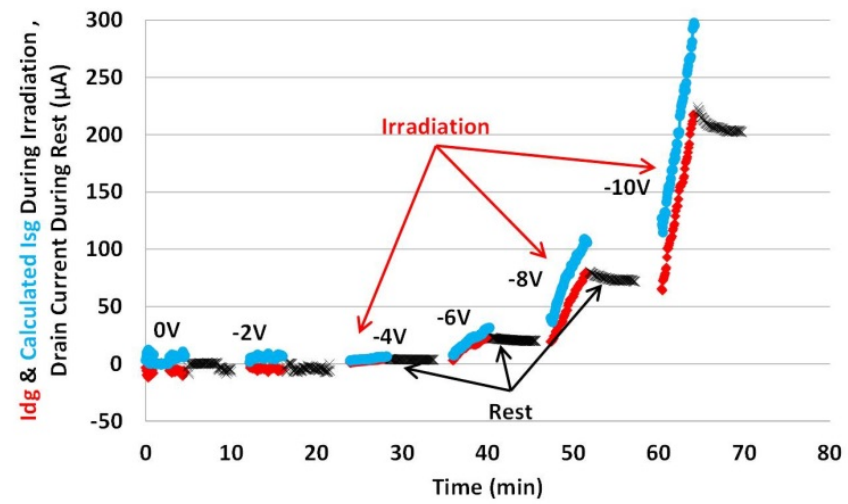

(b)

Figure 13: (a) Gate and (b) drain currents measured in situ with repeated Au irradiation. The calculated source-gate current is also shown in (b). Gate bias was decremented for each exposure from $0 \mathrm{~V}$ to $-10 \mathrm{~V}$ in $-2 \mathrm{~V}$ steps. The drain bias was kept at $0 \mathrm{~V}$ to keep the device from conducting drive current. 


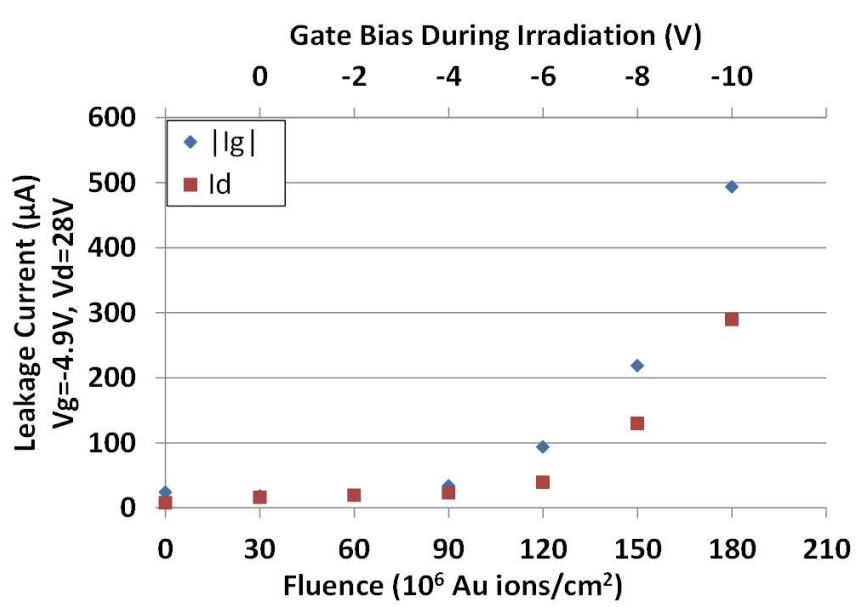

Figure 14: The leakage currents with respect to the irradiated gate bias are plotted. This data is from the gate voltage $-4.9 \mathrm{~V}$ and drain voltage $28 \mathrm{~V}$ data point for the Ig-Vg and Id-Vg sweep before each irradiation and at the conclusion of the test.

\section{4) Experiment 4-Gate bias - Drain On}

The purpose of this experiment is to observe changes in leakage currents with respect to gate bias; a 5 minute rest period followed each irradiation. During irradiation, the drain was biased to $28 \mathrm{~V}$. Gate bias was increased from $-4.5 \mathrm{~V}$ to $2.5 \mathrm{~V}$ in $1 \mathrm{~V}$ steps for repeated irradiations. Drain-to-source conduction increases rapidly as gate voltage increases above $-3.5 \mathrm{~V}$. The device was biased in pinch-off $(\mathrm{Vg}=-5 \mathrm{~V}$ and $\mathrm{Vd}=28 \mathrm{~V}$ ) for the rest period. An Ig-Vg sweep was done before each irradiation and at the conclusion of the experiment. Each exposure irradiated one part with $\mathrm{Au}$ to a fluence of $2.0 \times 10^{7}$ particles $/ \mathrm{cm}^{2}$. Results are shown in Figures $15 \& 16$.

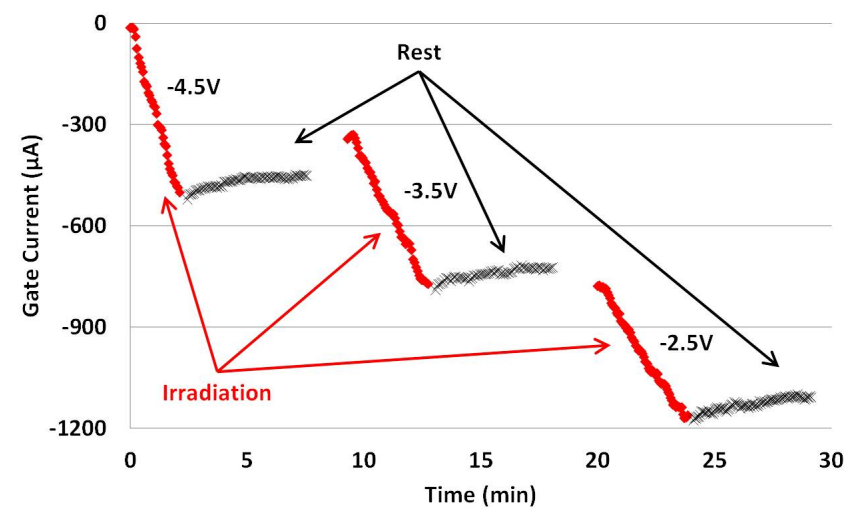

Figure 15: Gate current measured in situ with repeated $\mathrm{Au}$ irradiation. Gate bias was incremented for each exposure from $-4.5 \mathrm{~V}$ to $-2.5 \mathrm{~V}$ in $-1 \mathrm{~V}$ steps. Drain was biased to $28 \mathrm{~V}$.

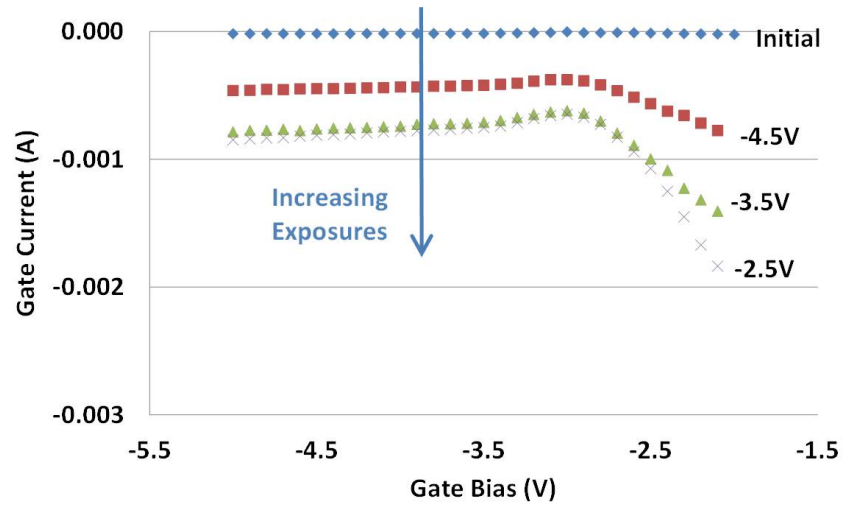

Figure 16: Gate current was measured versus a sweep of the gate bias before each irradiation and at the conclusion of the test. Drain was biased to $28 \mathrm{~V}$.

\section{5) Experiment 5 - Beam degrader}

The purpose of this experiment is to observe changes in leakage currents with respect to beam degrader condition; a 5 minute rest period followed each irradiation. The device was biased in pinch-off $(\mathrm{Vg}=-5 \mathrm{~V}$ and $\mathrm{Vd}=28 \mathrm{~V})$ during both irradiation and rest periods. Two exposures at each of three different degrader positions were tested. Table 4 shows the degrader conditions and resulting beam energy. An Ig-Vg and Id-Vg sweep was done before each irradiation and at the conclusion of the experiment. Each exposure irradiated one part with $\mathrm{Au}$ to a fluence of $2.0 \times 10^{7}$ particles $/ \mathrm{cm}^{2}$. Results are shown in Figures 17 - 19.

\begin{tabular}{lllc}
\multicolumn{2}{c}{ TABLE 4: TEST CONDITIONS OF BEAM DEGRADER EXPERIMENT. } \\
$\begin{array}{ll}\text { Al Degrader } \\
\text { Angle }\left(^{\circ}\right)\end{array}$ & $\begin{array}{l}\text { Al Degrader } \\
\text { Thickness (mil) }\end{array}$ & E0 $(\mathrm{MeV})$ & $\begin{array}{l}\text { LET on GaN } \\
\left(\mathrm{MeV} / \mathrm{mg} / \mathrm{cm}^{2}\right)\end{array}$ \\
\hline 60.0 & 2.000 & 301 & 63.4 \\
55.3 & 1.757 & 455 & 69.0 \\
0.0 & 1.000 & 915 & 72.5 \\
\hline
\end{tabular}

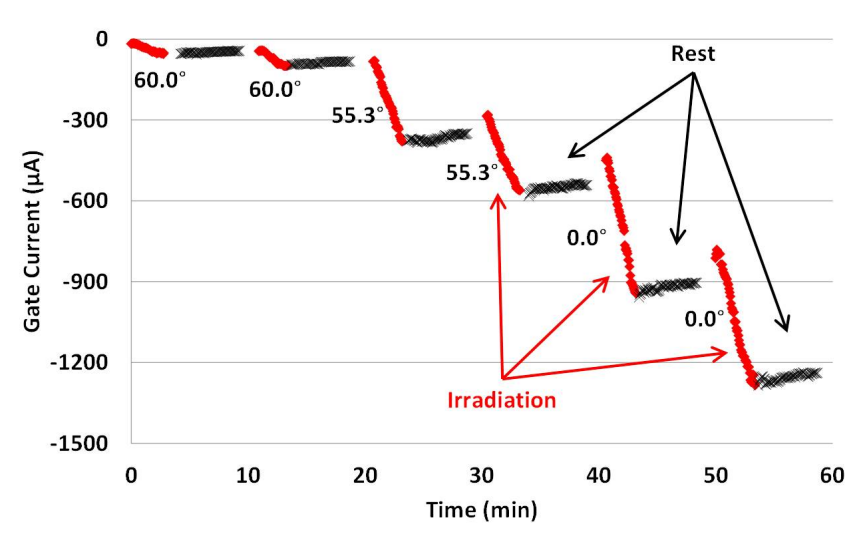

(a) 


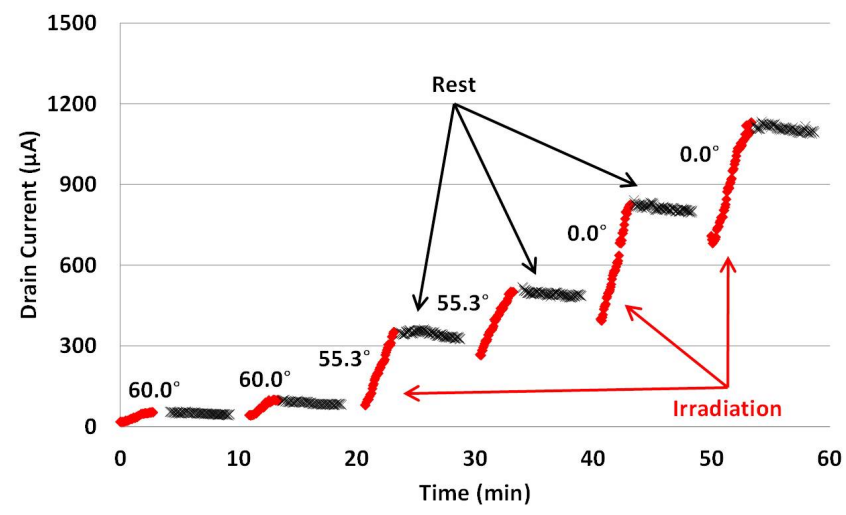

(b)

Figure 17: (a) Gate and (b) drain currents measured in situ with repeated $\mathrm{Au}$ irradiation. The DUTs were biased in pinch-off for both irradiations and rest periods.

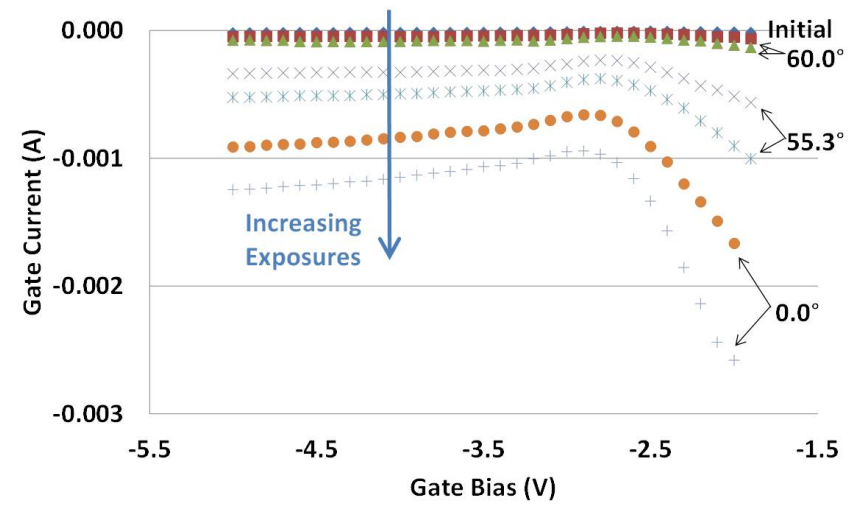

Figure 18: Gate current was measured versus a sweep of the gate bias before each irradiation and at the conclusion of the test. Drain was biased to $28 \mathrm{~V}$.

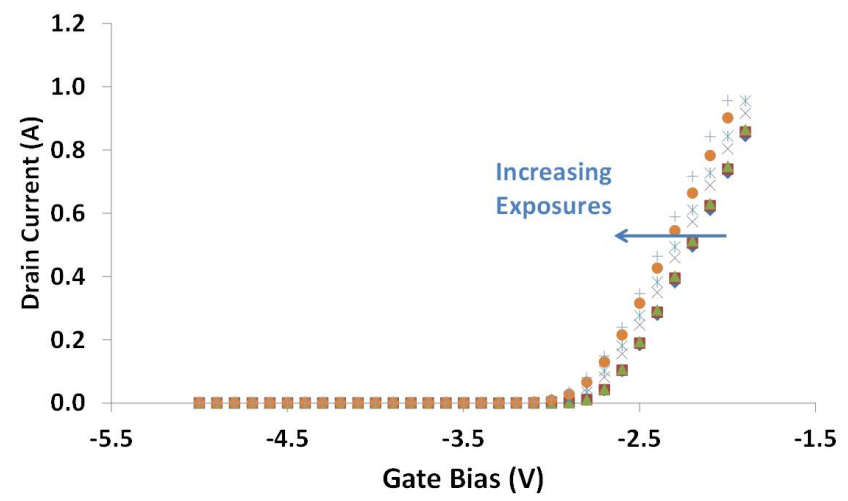

(a)

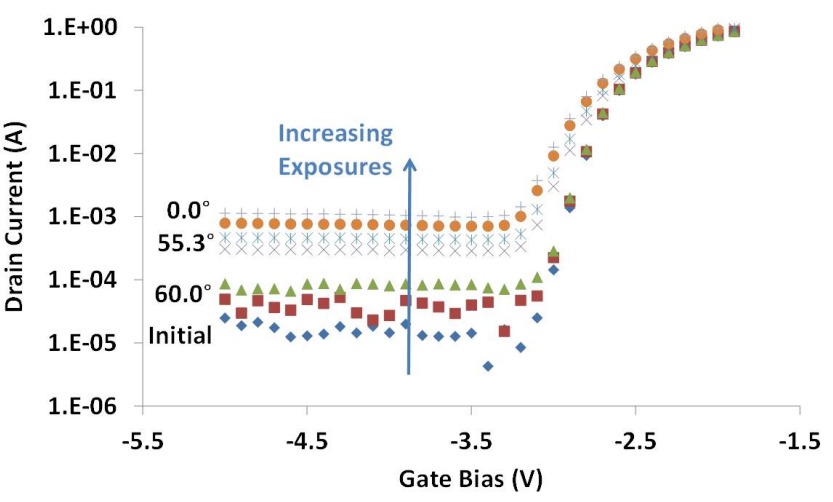

(b)

Figure 19: Drain current was measured versus a sweep of the gate bias before each irradiation and at the conclusion of the test. Drain was biased to 28 V. Drain current is plotted on a (a) linear and (b) semi-log scale.

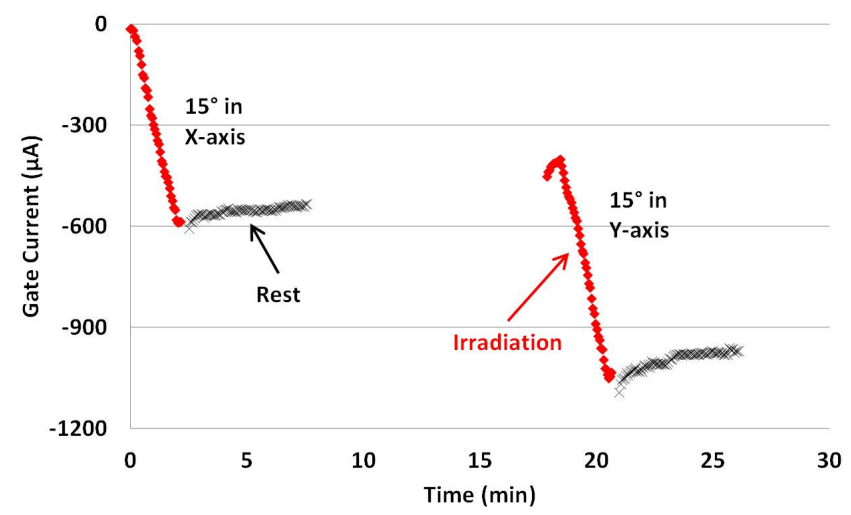

(a)

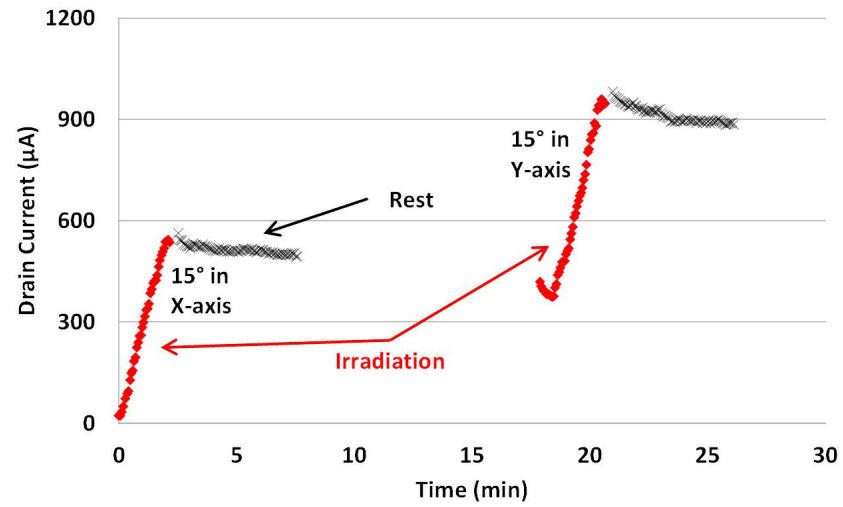

(b)

Figure 20: (a) Gate and (b) drain currents measured in situ with repeated $\mathrm{Au}$ irradiation. The DUTs were bias in pinch-off for both irradiations and rest periods.

\section{6) Experiment 6-DUT angle}

The purpose of this experiment is to observe changes in leakage currents with respect to DUT angle; a 5 minute rest period followed each irradiation. Due to limitations in the visibility if the exposed $\mathrm{GaN}$ die only an angle of $15^{\circ}$ off boresight was tested in both the $\mathrm{x}$-axis and $\mathrm{y}$-axis. The device was biased in pinch-off $(\mathrm{Vg}=-5 \mathrm{~V}$ and $\mathrm{Vd}=28 \mathrm{~V})$ during both irradiation and rest periods. An Ig-Vg sweep was done before each irradiation and at the conclusion of the experiment. Each 


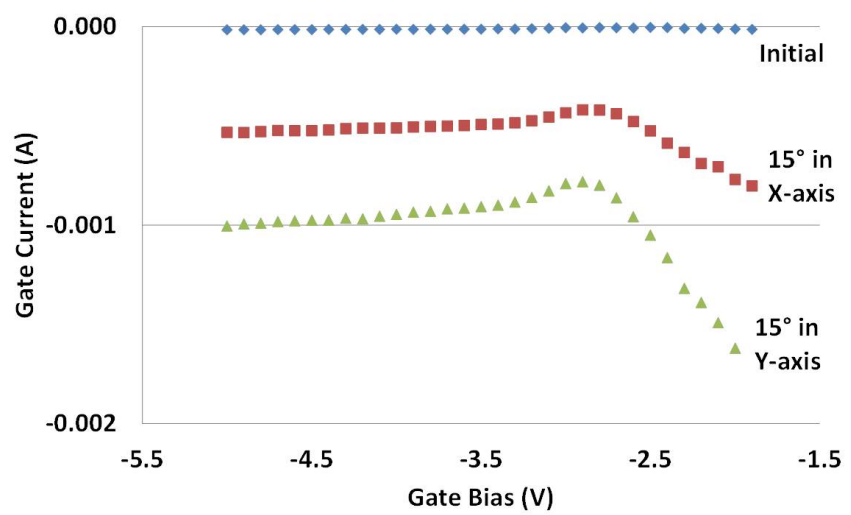

Figure 21: Gate current was measured versus a sweep of the gate bias before each irradiation and at the conclusion of the test. Drain was biased to $28 \mathrm{~V}$.

exposure irradiated one part with $\mathrm{Au}$ to a fluence of 2.0x $10^{7}$ particles $/ \mathrm{cm}^{2}$. Results are shown in Figures $20 \& 21$.

7) Experiment $7-R F$ drive

The purpose of this experiment is to observe changes in device operation when irradiated during RF operating conditions. The test setup was slightly modified to allow RF operation, and is shown in Figure 22. The equipment used is listed in Table 5. The device was biased to quiescent current $(250 \mathrm{~mA})$ and operated with a continuous $3.5 \mathrm{GHz}, 40 \mathrm{dBm}$ output power signal. Pinch-off condition biased rest periods were not performed between exposures. Also, Id-Vg and Ig$\mathrm{Vg}$ sweeps were not performed between exposures. The operating conditions for $\mathrm{P}_{\mathrm{SAT}}$ were checked prior to 5 successive irradiations, and no change was observed. Each exposure irradiated one part with $\mathrm{Au}$ to a fluence of $2.0 \times 10^{7}$ particles $/ \mathrm{cm}^{2}$. Results are shown in Figure 23.

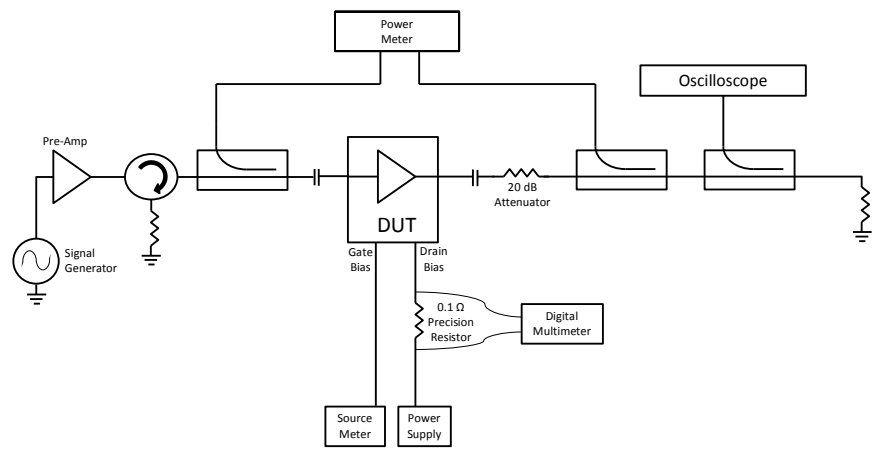

Figure 22: RF test setup used for experiment 7.

TABLE 5: TEST EQUIPMENT USED FOR RF HEAVY ION EXPERIMENTS

\begin{tabular}{ll} 
Test Equipment & Model \\
\hline Source Meter & Keithley 2410 \\
Power Supply & TDK Lambda Gen150-10 \\
Digital Multimeter & HP 3458A \\
Signal Generator & HP 83623B \\
Pre-Amplifier & Ophir 5162 \\
Power Meter & HP EPM-442A \\
(2x) Power Sensors (not shown) & (2x) HP ECP-E26A \\
Oscilloscope & Tektronix MSO72004C \\
\hline
\end{tabular}

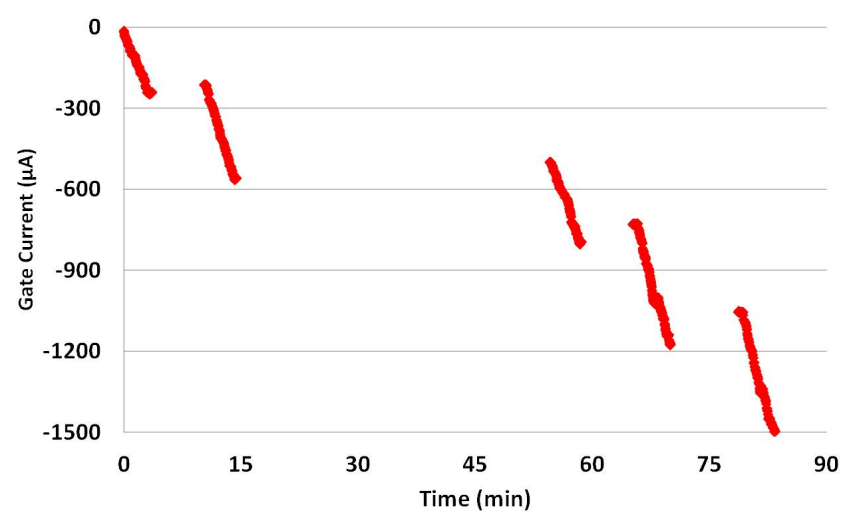

Figure 23: Gate current measured in situ with repeated Au irradiation. The DUTs were biased to a quiescent current of $250 \mathrm{~mA}$ and operated with a continuous $3.5 \mathrm{GHz}, 40 \mathrm{dBm}$ output power signal. Pinch-off condition biased rest periods were not performed between exposures.

8) Experiment 8 - Ions

The purpose of this experiment is to observe changes in leakage currents across repeated heavy ion exposures of different ion types. The devices were biased in pinch-off $(\mathrm{Vg}=-5 \mathrm{~V}$ and $\mathrm{Vd}=28 \mathrm{~V})$ during each exposure. Ig-Vg and Id-Vg sweeps were done before each irradiation and at the conclusion of the experiment. A fresh part was irradiated for each ion (Ta, Ho, Pr, Xe, and $\mathrm{Ag})$. Each exposure was taken to a fluence of $2.0 \times 10^{7}$ particles $/ \mathrm{cm}^{2}$. Results are shown in Figures 24 - 26.

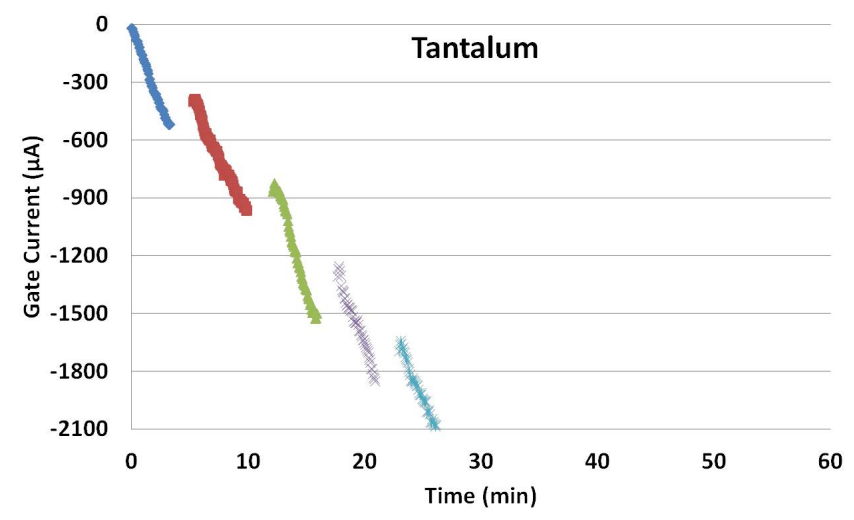

(a)

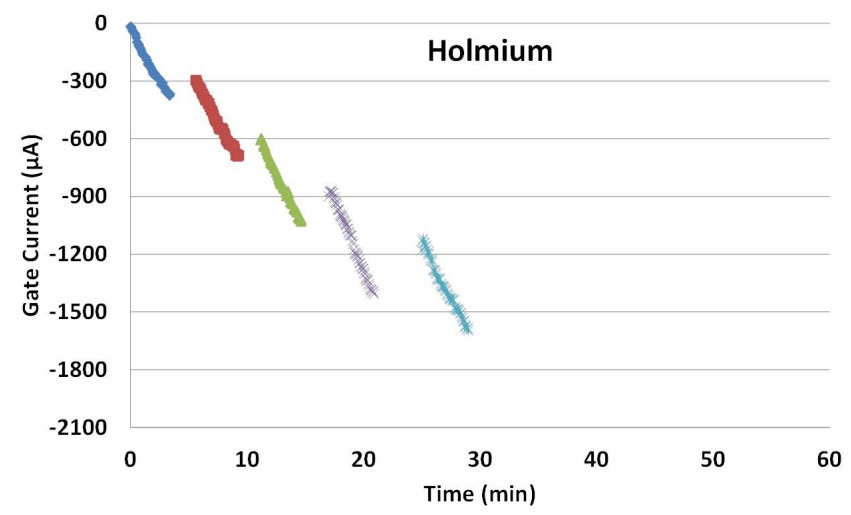

(b) 


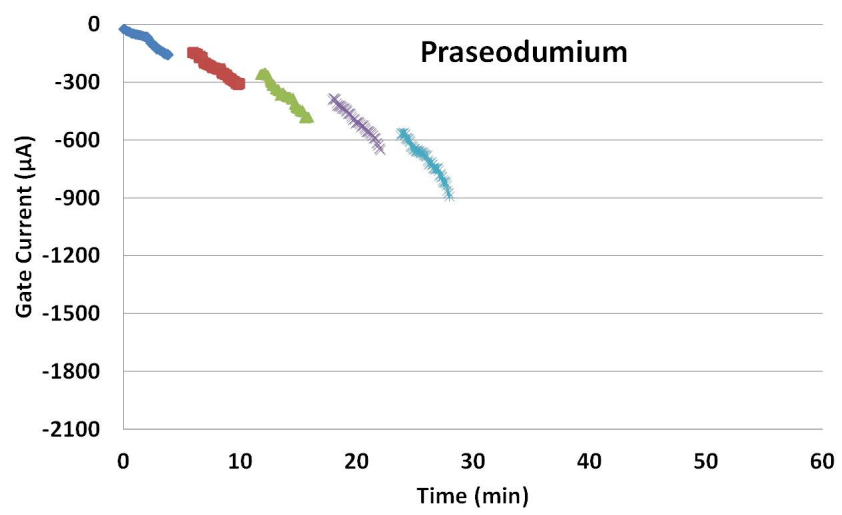

(c)

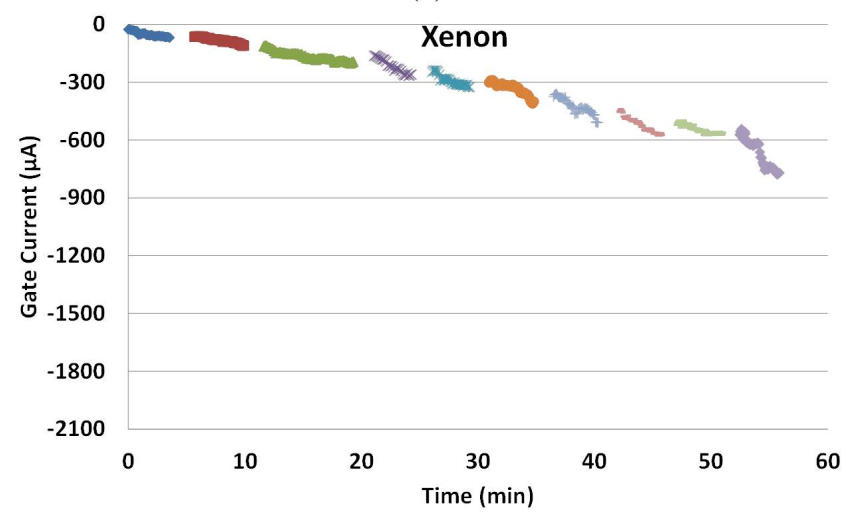

(d)

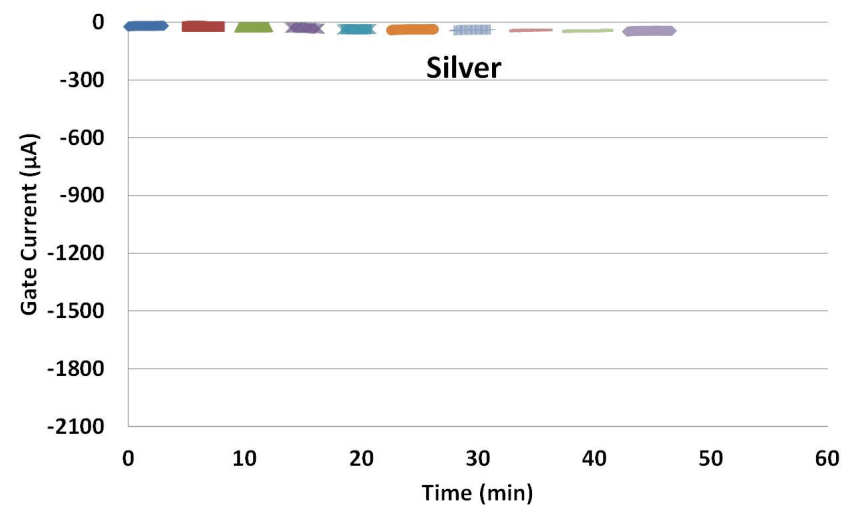

(e)

Figure 24: Gate current measured in situ with repeated (a) Ta, (b) Ho, (c) Pr, (d) Xe, and (e) Ag irradiation. The DUTs were bias in pinch-off for both irradiations and rest periods.

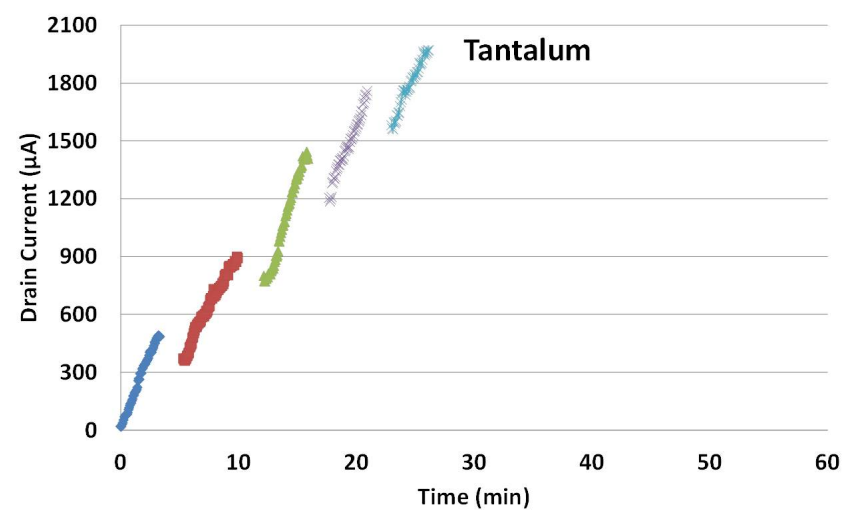

(a)

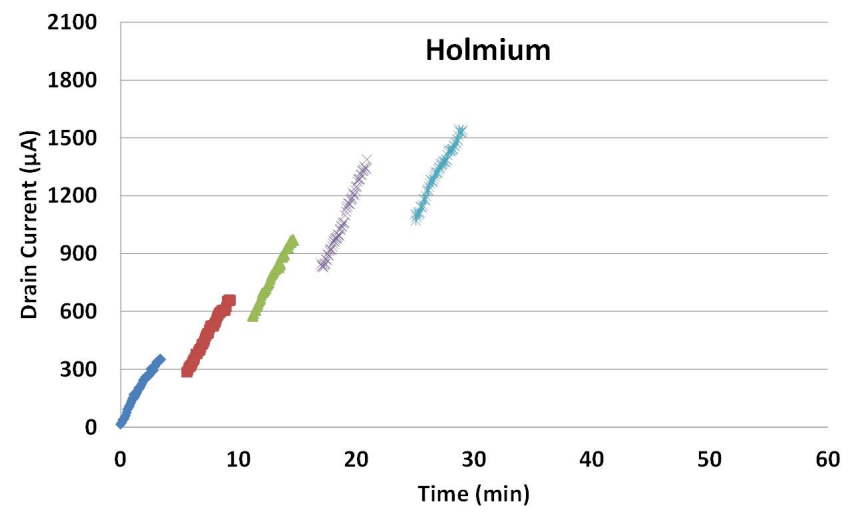

(b)

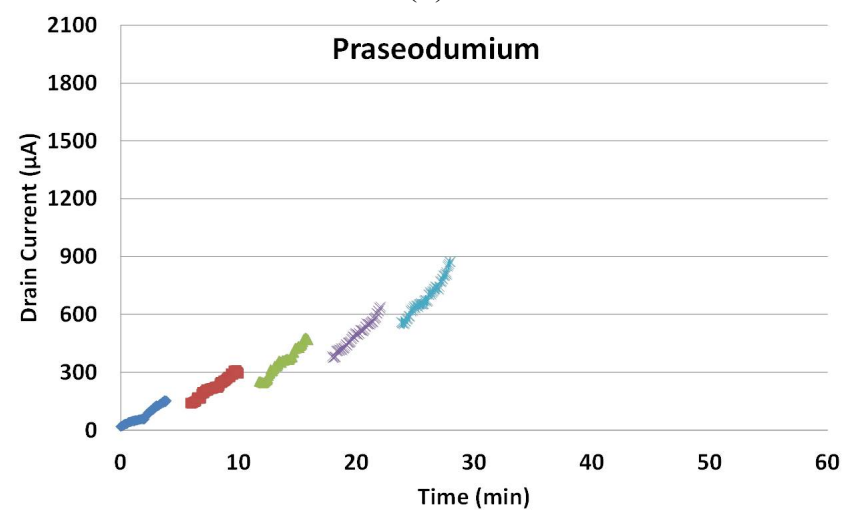

(c)

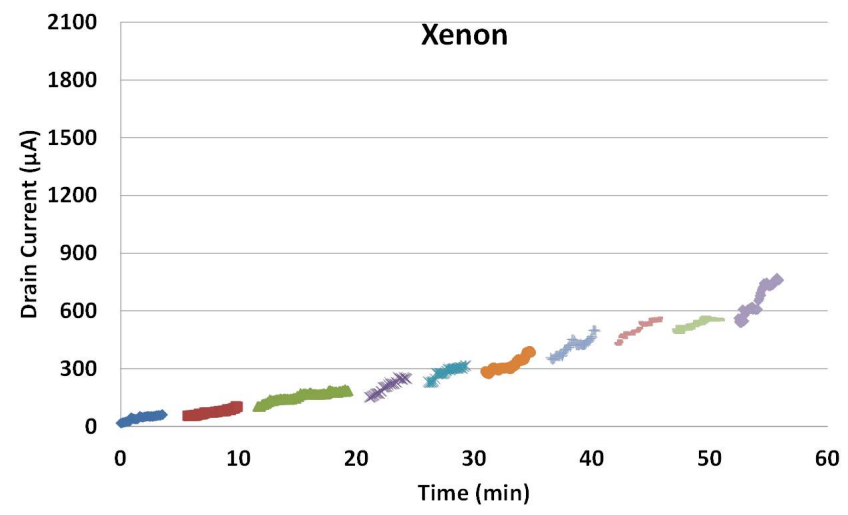

(d)

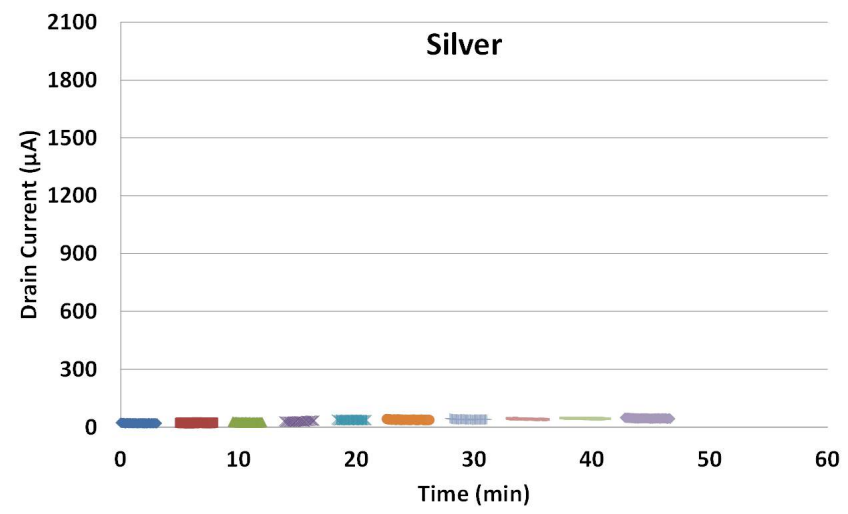

(e)

Figure 25: Drain current measured in situ with repeated (a) Ta, (b) Ho, (c) Pr, (d) Xe, and (e) Ag irradiation. The DUTs were bias in pinch-off for both irradiations and rest periods. 
Gate current values at $\mathrm{V}_{\mathrm{G}}=-4.9 \mathrm{~V}$ and $\mathrm{V}_{\mathrm{D}}=28 \mathrm{~V}$ for each ion type after each $2.0 \times 10^{7}$ particles $/ \mathrm{cm}^{2}$ exposure are plotted in Figure 26. Gate leakage increases more with higher LET ions, with minimal leakage demonstrated with Ag.

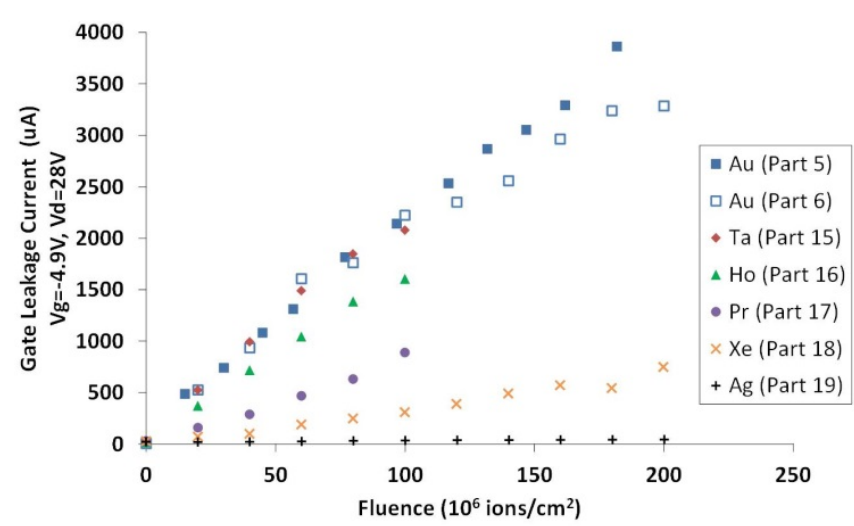

(a)

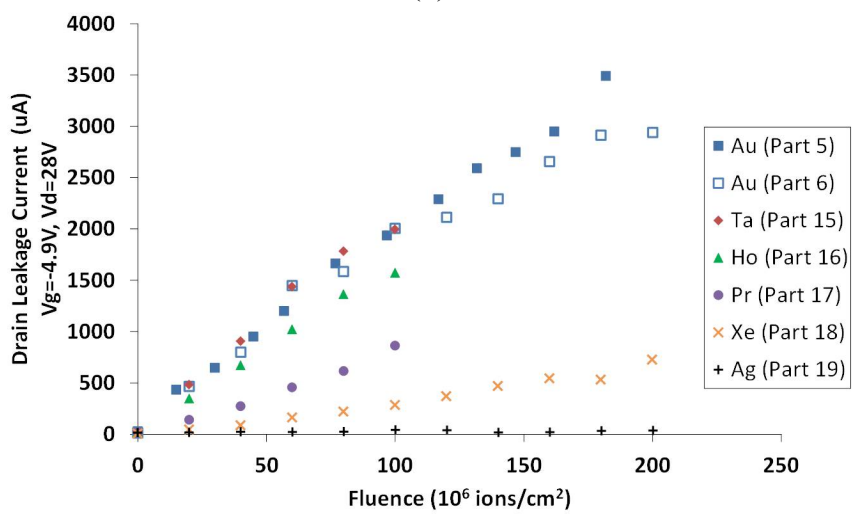

(b)

Figure 26: The (a) magnitude of gate current and (b) drain current at gate voltage $-4.9 \mathrm{~V}$ and drain voltage $28 \mathrm{~V}$ before each irradiation and at the conclusion of the test. Measurements performed for $\mathrm{Au}, \mathrm{Ta}, \mathrm{Ho}, \mathrm{Pr}, \mathrm{Xe}$, and Ag ions.

\section{DISCUSSION}

It is clear that there are leakage issues in the tested HEMT devices after high-fluence heavy ion exposures. The suite of data taken during this series of experiments is allowing for an in-depth analysis of the physical mechanisms behind the leakage current behavior. Unfortunately, this analysis is limited by the sample size, therefore requiring additional testing.

\section{REFERENCES}

[1] A. Ionascut-Nedelcescu, C. Carlone, A. Houdayer, H. J. von Bardeleben, J.-L. Cantin, and S. Raymond, "Radiation hardness of gallium nitride", IEEE Trans. Nucl. Sci., vol. 49, no. 6, pp. 2733 2738, Dec. 2002.

[2] S. Bazzoli, S. Girard, V. Ferlet-Cavrois, J. Baggio, P. Paillet, and O. Duhamel, "SEE sensitivity of a COTS GaN transistor and silicon MOSFETs," Proc. 9th Eur. Conf. Radiation and Its Effects on Components and Systems (RADECS), pp. 1 - 5, Deauville, France, Sept. 10-14, 2007.

[3] S. Kuboyama, A. Maru, H. Shindou, N. Ikeda, T. Hirao, H. Abe, T. Tamura, "Single-Event Damages Caused by Heavy Ions Observed in AlGaN/GaN HEMTs," IEEE Trans. Nucl. Sci., vol. 58, no. 6, pp. 2734 -2738 , Dec. 2011.

[4] S. E. Armstrong, H. Bradley, K. Bole, E. Johnson, J. Staggs, W. Shedd, C. H. Rice, J. D. Ingalls, C. C. Hedge, A. R. Duncan, and B. D. Olson, "Heavy Ion Testing of Commercial Gallium Nitride Transistors in the Radio Frequency Spectrum," Submitted to the Radiation Effects Data Workshop (REDW) in conjunction with the 2015 Nuclear Science and Radiation Technology Conference, Boston, MA, 2015.

[5] R. S. Pengelly, S. M. Wood, J. W. Milligan, S. T. Sheppard, W. L. Pribble, "A Review of $\mathrm{GaN}$ on $\mathrm{SiC}$ High Electron-Mobility Power Transistors and MMICs," IEEE Trans. Microwave Theory and Techniques, vol. 60, no. 6, pp. 1764-1783, June 2012. 